\title{
The results of research on tillage rollers with an economic assessment of the effectiveness of their use
}

\author{
Ivan Sharonov*, Vladimir Kurdyumov, Yuri Isaev, and Viktor Kurushin \\ Ulyanovsk State Agrarian University named after P.A. Stolypin, Ulyanovsk, RUSSIA
}

\begin{abstract}
The study confirmed the set scientific hypothesis that to improve seed germination and uniformity of germination of cultivated agricultural crops and increase their yields possible while performing operations field preparation, sowing, formation of the desired profile, density and structure of the soil over the sown seeds on the basis of application of innovative methods and means of mechanization of surface tillage. As a result of experimental studies, the design parameters of the developed innovative agricultural tools have been optimized. When combined, they provide the required fine-grained and optimally compacted soil layer, in which the seeds of agricultural crops are located. As recommendations to agricultural production, the actual value of the specific mass of the developed rollers is established, taking into account ballasting loads per $1 \mathrm{~m}$ of the width of the grip, the value of which is within $95 \ldots 160 \mathrm{~kg}$, depending on the shape and design of the working elements, as well as on the properties of the processed medium. In the course of evaluating the metal capacity of innovative agricultural tools and serial ring-spur roller, a difference of 64 $\%$ per unit of widthof the grip was revealed. Defined increase of productivity when using the developed means of mechanization of surface tillage for spring barley to $14 \%$ and $16 \%$, spring wheat by $11 \%$ and $14 \%$, winter wheat up to $7 \%$ and $9 \%$ respectively compared with serial ring-spur roller and disc rollers seeder. Based on the economic assessment of the compared seeding technologies, the annual economic effect of the introduction of innovative tillage rollers was established, which amounted to $64 . . .69$ \$ by 1 ha of spring barley crops.
\end{abstract}

Production of competitive agricultural products is primarily associated with the introduction of resource-saving technologies for cultivating crops that ensure stable yields at minimal energy costs, with the preservation and improvement of soil fertility and compliance with the principles of environmental management [1]. At the same time, an important scientific problem remains the low field germination of cultivated crops in comparison with the laboratory (the field germination of seeds of winter crops is less than the laboratory by $17 . . .18 \%$, spring crops - up to $25 \%$ ). This leads to a shortfall in the yield of cultivated crops by an average of $0.5 \ldots 1.1 \mathrm{t} / \mathrm{ha}$, which causes a decrease in profit to $50 \ldots 120 \$ /$ ha. The reason for this is the poor quality of tillage and seeding, which is due to

\footnotetext{
* Corresponding author: ivanshar2009@yandex.ru
} 
the imperfect design of tillage tools and seeding machines. In addition, an increase in the timing of spring field work leads to a decrease in the yield of cultivated crops due to the appearance of time gaps between technological operations. This is due to the lack of highly efficient, resource-saving means of mechanization of seeding and tillage for agricultural producers.

In connection with the above, the problem of mechanical and technological justification for improving energy efficiency and environmental friendliness of crop cultivation methods and competitive means of mechanization of surface tillage and seeding, ensuring high quality of technological operations, optimal technical and economic indicators, is relevant, important and has a significant impact on the development of the agrial production.

Scientific hypothesis: to increase the field germination of seeds and the uniformity of seedlings of cultivated crops and increase their productivity is possible when simultaneously performing field preparation operations, sowing, forming the required profile, density and structure of the soil over the sown seeds through the use of innovative methods and means of mechanization of surface tillage.

The purpose of the research is to develop energy-resource-saving methods and means of mechanization of surface soil treatment with justification of optimal design parameters and operating modes that reduce energy and operating costs, the required quality of soil treatment taking into account environmental requirements and, as a result, increase the yield of cultivated crops.

Such a negative phenomenon as uneven seedlings and low field germination of seeds significantly reduces productivity. One of the well-established factors of uneven germination and low field germination of seeds is surface treatment of the soil during sowing in order to compact and structure it. Under the influence of tillage rollers on the soil the necessary density of the seed layer and the rise of moisture from the lower layers due to the formation of a capillary structure is provided for agricultural seeds. Rolling agricultural tools should grind large soil aggregates and smooth the microrelief of the field [2, 3]. Consequently, the operation of post-seeding compaction and structuring of the soil layer in the seed zone becomes an important aspect of agricultural cultivation, ensuring the uniformity of seedlings.

For the formation of melkonarezannogo, structured and optimal-compacted soil layer at sowing of agricultural products considering the technological requirements of the process designed slatted-cylinder, slatted-hammer, wave, cylindrical-spiral, eccentric tools (fig. 1), the predominant differences which are combination to different effects of their working bodies on the ground, as well as low, in comparison with existing rollers, the metal consumption of the design $[4,5,6,7,8]$.

Theoretical studies of the process of surface tillage allowed us to establish quantitative and qualitative relationships between the parameters that change in the process of tillage and the parameters of the developed means of mechanization, as well as to justify the requirements for the working bodies of tools for surface tillage.

As a result of experimental studies, the design parameters of the presented agricultural tools were optimized. The criterion for evaluating the quality of processing is a universal indicator - the criterion of compliance standard CCS with the for the density and structure of the sown soil layer [9]. While ensuring that the density and structure of soil agrotechnical requirements $\operatorname{CCS}=1$, in this case, the soil density $\rho=1200 \mathrm{~kg} / \mathrm{m}^{3}$, and aggregate composition of seed layer is represented by a fraction with sizes from $0.25 \mathrm{~mm}$ to $50 \mathrm{~mm}$ (with a minimum content in the sample of dust particles smaller than $0.25 \mathrm{~mm}$ and the absence of large aggregates greater than $50 \mathrm{~mm}$ ). 


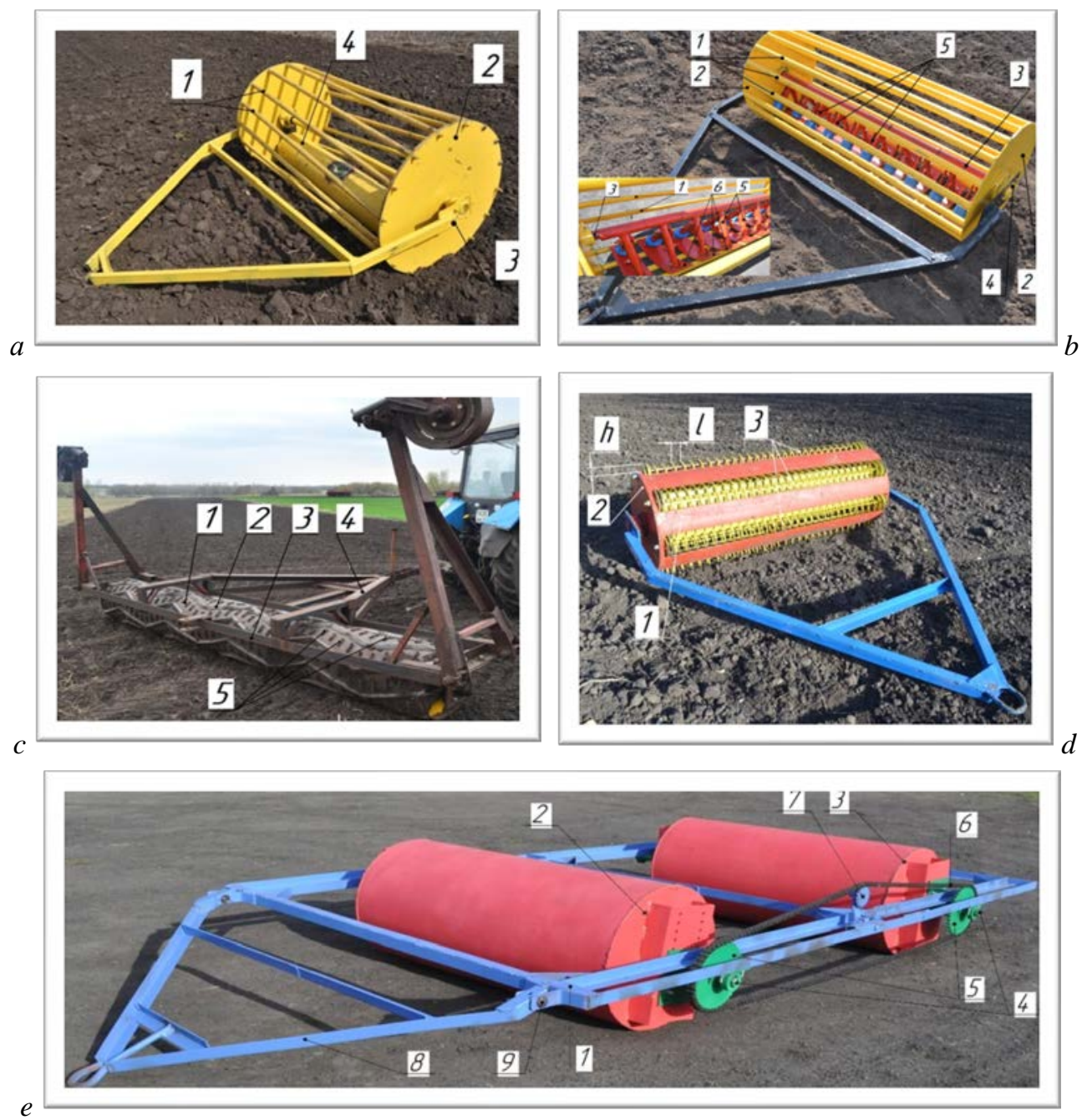

$a$ - slatted-cylinder roller: 1 - tubular slats, 2 - end disks, 3 - coupling mechanism, 4 - hollow ballasting cylinder; $b$ - slatted-hammer roller: 1 - tubular slats; 2 - end disks, 3 - axis, 4 - bearing support, 5 - telescopic leads, 6 - segment hammers; $c$ - wave roller: 1 - hollow ballasted cylinder, 2 V-shaped protrusions, 3 - frame, 4 - coupling mechanism with a stop, 5 - fingers; $d$ - cylindricalspiral roller: 1 - hollow cylinder, 2 - end disks, 3 spiral working bodies; $e$ - eccentric roller: 1 -frame, 2, 3 - hollow cylinders, 4 - half-axes, 5 -sprockets, 6 - roller chain, 7 - tensioning sprocket, 8 coupling device, 9 - hinge

Fig. 1. Innovative tillage rollers

Got the following results: for slatted-cylinder roller $\mathrm{CCS}=0,8$ is achieved at a speed of $10 \mathrm{~km} / \mathrm{h}$, the distance from the slats to the ballasting hollow cylinder $9 \mathrm{~mm}$ and the weight of the ballast in the cylinder of $16 \mathrm{~kg}$; for slatted-hammer rink $\mathrm{CCS}=0,81$ - at a speed of $11 \mathrm{~km} / \mathrm{h}$, the distance from the slats to the ballasting hollow cylinder $10 \mathrm{~mm}$ and the mass of the ballast hammers $1.7 \mathrm{~kg}$; for the wave of the rink CCS $=0,84$ is achieved at a speed of $11 \mathrm{~km} / \mathrm{h}$ and the ballast weight $78 \mathrm{~kg}$; for the cylindrical-helical rink CCS $=0.82$ at speed of $11 \mathrm{~km} / \mathrm{h}$, the mass of ballasting of cargo of $100 \mathrm{~kg}$, step spiral spiral spiral of the working body $40 \mathrm{~mm}$, the departure of the spiral screws $35 \mathrm{~mm}$; for eccentric rink CCS = 0,86 is achieved when the speed of the unit $11.7 \mathrm{~km} / \mathrm{h}$, the mass of ballasting of cargo 126 
$\mathrm{kg}$ and the eccentricity of the axes of $60 \mathrm{~mm}$. It should be noted as recommendations for the agricultural production that the specific gravity rollers designed with consideration of ballasting of cargo per $1 \mathrm{~m}$ width is in the range of $95 . . .160 \mathrm{~kg}$ depending on the shape and design of the working elements, and the properties of the treated medium.

After rolling with the developed rollers (in comparison with the control experience, when processing with a mass-produced ring-spur roller), the content of soil lumps less than $0.25 \mathrm{~mm}$ was 18,2...19,5 \% (20,4 \%), 0,25...10 mm - 63,9...67,1 \% (55,3 \%), 10...50 mm $12,2 \ldots 14,6 \%$ (19 \%), more than 50 - $0 \%$ (5.3 \%), and the density of the soil in layers with multiple measurements averaged $0 \ldots 3 \mathrm{~cm}-1108 \ldots 1120 \mathrm{~kg} / \mathrm{m}^{3}\left(1089 \mathrm{~kg} / \mathrm{m}^{3}\right), 3 \ldots 6 \mathrm{~cm}-$ 1198...1219 kg/m $\mathrm{m}^{3}\left(1178 \mathrm{~kg} / \mathrm{m}^{3}\right), 6 \ldots 9 \mathrm{~cm}-1396 \ldots 1448 \mathrm{~kg} / \mathrm{m}^{3}\left(1368 \mathrm{~kg} / \mathrm{m}^{3}\right)$. For a ringspur roller, the CCS indicator is 0.74 . Therefore, under equal initial conditions of the experiment, the proposed rollers in comparison with their analogues provide a higherquality fractional composition and soil density close to the optimum. The structure of the soil composition is small-lumpy without large soil aggregates and fully provides the necessary conditions for the development of the root system of agricultural crops, as well as contributes to the better preservation of moisture in the seed location zone. This leads to an increase in the field germination of seeds, ensuring the uniformity of seedlings of cultivated crops and, as a result, increasing their productivity. At the same time, the specific metal content of the proposed agricultural tools does not exceed $130 \mathrm{~kg}$ per $1 \mathrm{~m}$ of working width, which is 2.3 times less than that of the ring-spur roller $3 K K S h-6(283.6 \mathrm{~kg} / \mathrm{m})$.

To confirm the scientific hypothesis, studies were conducted in real field conditions under the crops of spring wheat (grade - Simbircit), winter wheat (grade - Saratovskaya-17) and spring barley (grade - Nutans-553). At the initial stage, after sowing and rolling, the state of seedlings in the experimental plots was compared. The results of a qualitative assessment of seedlings are presented on the example of winter wheat crops after processing with annular address rollers of the SZ-5,4 seeder (fig. 2, a), a waves roller (fig. $2, b$ ), an eccentric roller (fig. 2, c), a slatted roller (fig. 2, $d$ ) and a mass-produced and most common in the region ring-spur roller (fig. $2, e$ ).

The comparative results of evaluating the uniformity of winter wheat seeding after treatment with different rollers are presented in table 1.

Table 1. Indicators that characterize the uniformity of seeding depth

\begin{tabular}{|c|c|c|c|c|c|c|c|c|c|}
\hline \multicolumn{10}{|c|}{ Depth of seeding, $\mathrm{mm}$} \\
\hline \multicolumn{5}{|c|}{ After treatment with a ring-spur roller } & \multicolumn{5}{|c|}{ After processing with the developed rollers } \\
\hline 30 & 32 & 43 & 61 & 40 & 55 & 53 & 67 & 63 & 55 \\
\hline 60 & 55 & 60 & 45 & 50 & 53 & 61 & 55 & 53 & 67 \\
\hline 30 & 60 & 70 & 80 & 62 & 60 & 55 & 63 & 53 & 61 \\
\hline 39 & 47 & 73 & 78 & 71 & 58 & 54 & 64 & 65 & 51 \\
\hline \multicolumn{4}{|c|}{ Maximum value, mm } & 80 & \multicolumn{4}{|c|}{ Maximum value, $\mathrm{mm}$} & 67 \\
\hline \multicolumn{4}{|c|}{ Minimum value, $\mathrm{mm}$} & 30 & \multicolumn{4}{|c|}{ Minimum value, mm } & 51 \\
\hline \multicolumn{4}{|c|}{ Average value, $\mathrm{mm}$} & 54,3 & \multicolumn{4}{|c|}{ Average value, $\mathrm{mm}$} & 58,3 \\
\hline \multicolumn{4}{|c|}{ Range of variations, $\mathrm{mm}$} & 50 & \multicolumn{4}{|c|}{ Range of variations, $\mathrm{mm}$} & 16 \\
\hline \multicolumn{4}{|c|}{ Average linear deviation, $\mathrm{mm}$} & 13,2 & \multicolumn{4}{|c|}{ Average linear deviation, $\mathrm{mm}$} & 4,6 \\
\hline \multicolumn{4}{|c|}{ Dispersion } & 2,48 & \multicolumn{4}{|c|}{ Dispersion } & 0,27 \\
\hline \multicolumn{4}{|c|}{ Standard deviation } & 1,57 & \multicolumn{4}{|c|}{ Standard deviation } & 0,52 \\
\hline \multicolumn{4}{|c|}{ Coefficient of variation } & 0,29 & \multicolumn{4}{|c|}{ Coefficient of variation } & 0,09 \\
\hline
\end{tabular}

After analyzing the state of winter wheat seedlings, we found that after processing crops with the proposed and mass-produced tillage tools, the interval of variation of the values of the depth of seeding is respectively $68 \%$ less, and the average linear deviation is $65 \%$ less. Also, other indicators indicate a more uniform distribution of seeds by depth after processing with the proposed agro-tools in comparison with widespread analogues. 
As a result of calculations of indicators that characterize the uniformity of the depth of seeding, it can be concluded that the uneven seeding of cultivated crops in depth for the compared tools is characterized by a three-fold difference in the values of indicators. This reflects the positive impact of the application of the developed rollers in comparison with the existing ring-spur and address ring rollers of the seeder.
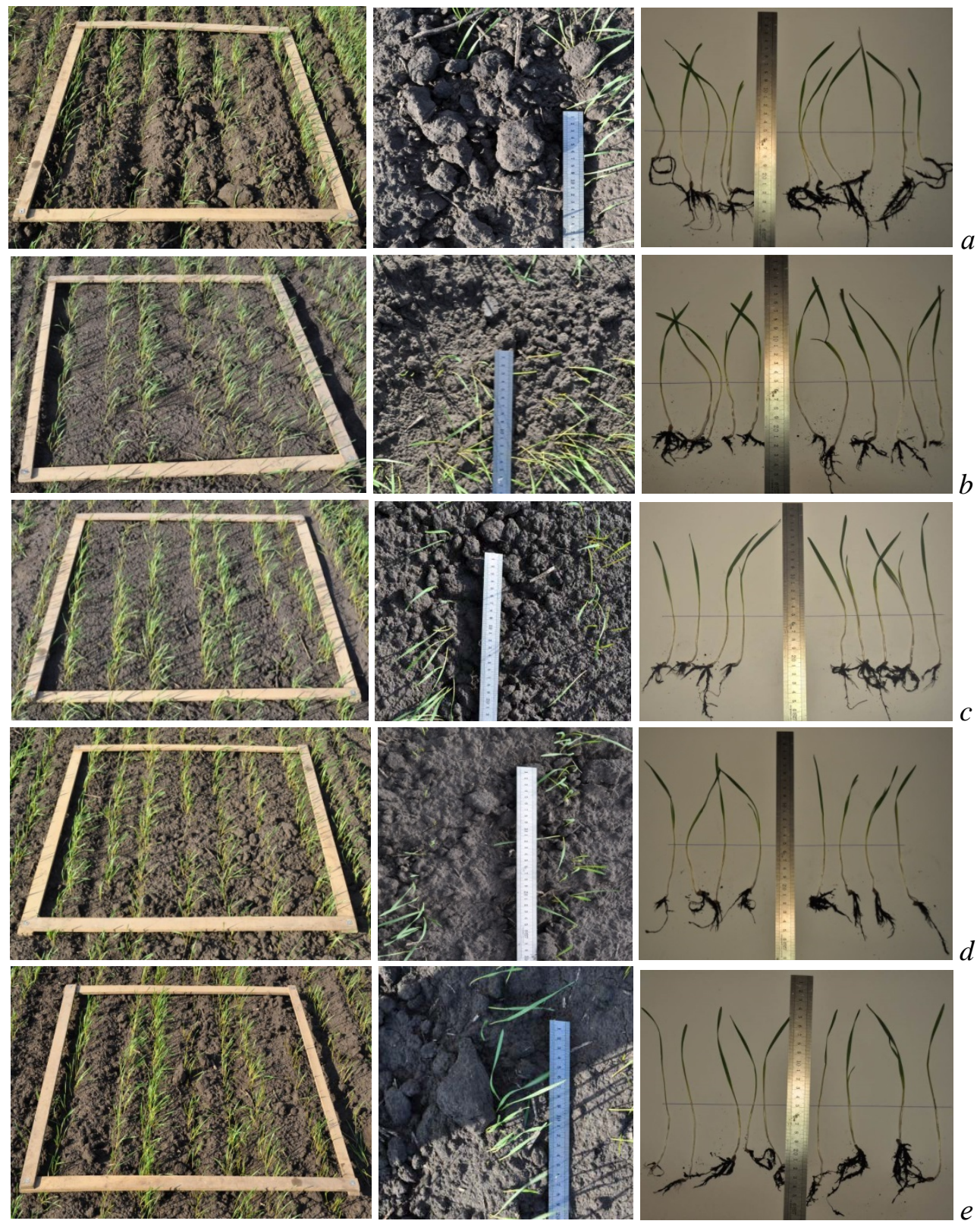

a - processing with address disk rollers of the SZ-5,4 seeder; b - processing with a wave roller; c processing with an eccentric tool; $d$ - processing with a slat-cylinder roller; e - processing with a ringspur roller

Fig. 2. Winter wheat seedlings after processing with different rollers. 
Similarly, the calculation was performed to assess the different quality of wheat seedlings by height, on the basis of which we obtained a 3.4-fold difference in similar estimates. In addition, an increase in seed germination by $3.4 \%$ was found in areas treated with new rollers, in comparison with non-rolled areas. Therefore, having provided uniform sealing of seeds in depth, we get the required uniformity of seedlings after processing with the proposed rollers, and also increase the field germination of seeds, which confirms the first part of the formulated scientific hypothesis.

After processing the results of production studies, an increase in productivity was revealed when using the developed means of mechanization of surface tillage of spring barley up to $14 \%$ and $16 \%$, spring wheat - up to $11 \%$ and $14 \%$, winter wheat - up to $7 \%$ and $9 \%$ compared with the use of serial ring-spur rollers and address ring rollers of the seeder respectively (fig. 3).

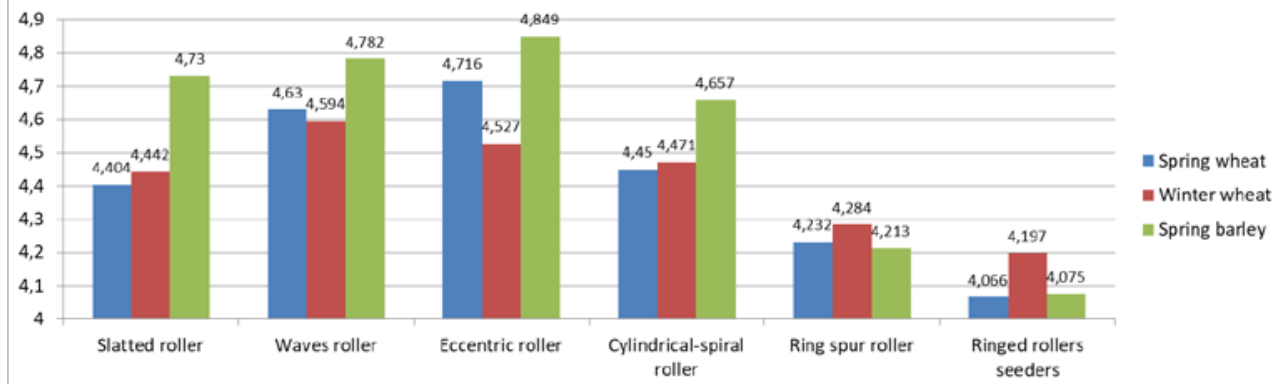

Fig. 3. Crop yield after processing with different rollers, t/ha.

In the course of evaluating the economic efficiency of implementing the proposed means of mechanization, we compared the proposed version, in which the developed rollers are part of a combined seeding unit, with the basic technology. According to the basic version, seeds are sown with the SZ-5,4 seeder equipped with address disk rollers. The second base for comparison, as the most common, took the option of seeding with a Sz-5,4 seeder, after which a separate operation is performed by rolling serial ring-spur rollers 3KKSh-6. The results of evaluating the economic efficiency of using technologies are given for sowing barley of the Nutans-553 variety (table 2).

Table 2. Indicators of economic efficiency of implementation of surface tillage mechanization tools.

\begin{tabular}{|c|c|c|c|c|c|c|}
\hline \multirow[b]{2}{*}{ Name of indicators } & \multicolumn{4}{|c|}{$\begin{array}{l}\text { Combined seeding unit (SZ-5,4 } \\
\text { with developed rollers) }\end{array}$} & \multirow[b]{2}{*}{$\begin{array}{c}\text { Seeder } \\
\text { SZ-5,4 + } \\
\text { rollers } \\
\text { 3KKSh-6 }\end{array}$} & \multirow{2}{*}{$\begin{array}{l}\text { Seeder } \\
\text { SZ-5,4 with } \\
\text { the base } \\
\text { address of } \\
\text { disk rollers }\end{array}$} \\
\hline & 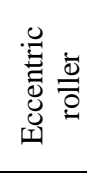 & 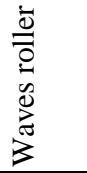 & 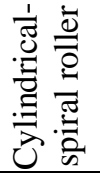 & 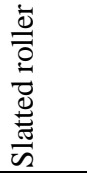 & & \\
\hline Sown area, ha & 100 & 100 & 100 & 100 & 100 & 100 \\
\hline Seeder price, \$ & \multicolumn{6}{|c|}{5500} \\
\hline $\begin{array}{l}\text { Additional capital investment } \\
\text { for the production/purchase of } \\
\text { rollers, \$ }\end{array}$ & 1643 & 1000 & 1205 & 917 & 3082 & - \\
\hline $\begin{array}{c}\text { Annual savings in operating } \\
\text { costs, \$ }\end{array}$ & 73 & 104 & 85 & 107 & - & 2962 \\
\hline $\begin{array}{l}\text { Increase in productivity, } \\
\mathrm{kg} / \mathrm{ha}\end{array}$ & 774 & 707 & 582 & 655 & 138 & - \\
\hline $\begin{array}{l}\text { Additional profit from sales } \\
\text { of product, } \$\end{array}$ & 8482 & 7747 & 6378 & 7178 & 1512 & - \\
\hline Annual economic benefit, \$ & 6910 & 6852 & 5257 & 6367 & - & - \\
\hline
\end{tabular}


Based on the analysis of the data shown in table 2, it can be concluded that when using a combined seeder unit with developed tillage rollers, operating costs are reduced by $73 . . .107$ \$ compared to the basic options. Due to the increase in crop yield, the profit from sales of products increases by $6378 \ldots 8482 \$$. As a result, the annual economic effect is $64 . .69$ \$ per 1 ha of barley crops.

Thus, the research confirmed the scientific hypothesis that it is possible to increase the field germination of seeds and the uniformity of seedlings of cultivated crops and increase their productivity while simultaneously performing field preparation operations, sowing, forming the required profile, density and structure of the soil over the sown seeds through the use of innovative methods and means of mechanization of surface tillage. The design parameters of the developed innovative agricultural tools have been optimized, when combined, they provide the required quality of the top layer of soil in which the seeds of agricultural crops are located. As recommendations to agricultural production, the actual value of the specific mass of the developed rollers is established, taking into account ballasting loads per $1 \mathrm{~m}$ of the width of the grip, the value of which is within $95 \ldots 160 \mathrm{~kg}$, depending on the shape and design of the working elements, as well as on the properties of the processed medium. At the same time, the specific metal content of the proposed agricultural tools does not exceed $130 \mathrm{~kg}$ per $1 \mathrm{~m}$ of working width, which is 2.17 times less in comparison with the well-known and widely used ring-spur roller 3KKSh-6. An increase in the yield of cultivated crops up to $16 \%$ was revealed when using the developed means of mechanization of surface tillage in comparison with the use of serial ring-spur rollers and address ring rollers of the seeder respectively. The annual economic effect of the introduction of innovative tillage agro-tools amounted to $64 . . .69$ \$ per 1 ha of spring barley crops.

\section{References}

1. N.E. Rudenko, K.D. Padalin, How to reduce energy costs and improve the quality indicators under continuous tillage, Vestnik APK Stavropol, № 1(13), pp. 66-68 (2014).

2. V.A. Milyutkin, S.A. Tolpekin, Innovative achievements of science and technology of the agro-industrial complex, Kinel, pp. 641-644 (2018).

3. S.G. Mudarisov, I.I. Gabitov, Y.P. Lobachevsky, N.K. Mazitov, R.S. Rakhimov, R.R. Khamaletdinov, I.R. Rakhimov, I.M. Farkhutdinov, A.M. Mukhametdinov, R.T. Gareev, Soil \& Tillage Research, v. 190 pp. 70-77 (2019).

4. V.I. Kurdyumov, I.A. Sharonov, V.E. Proshkin, E.N. Proshkin, Tillage roller, Patent No. 129331 Russian Federation, publ. 27.06.2013, byul. 18.

5. V.I. Kurdyumov, I.A. Sharonov, V.E. Proshkin, E.N. Proshkin, V. E. Kushnikov, Tillage roller, Patent No. 2617582 Russian Federation, publ. 25.04.2017, byul. 12.

6. V.I. Kurdyumov, I.A. Sharonov, V.E. Proshkin, E.N. Proshkin, Tillage roller, Patent No. 2489828 Russian Federation, publ. 20.08.2013, byul. 23.

7. V.I. Kurdyumov, I.A. Sharonov, A.S. Egorov, Tool for soil rolling, Patent No. 2564486 Russian Federation, publ. 10.10.2015, bull. 28.

8. V.I. Kurdyumov, I.A. Sharonov, A.S. Egorov, Tool for soil rolling, Patent No. 2567207 Russian Federation, publ. 10.11.2015, byul. 31.

9. A.K. Subaeva, A.A. Zamaidinov, V.I. Kurdyumov, E.S. Zykin, Quality control indicators of soil ridges at sowing cultivated crops, International Journal of Pharmacy and Technology. - v. 8, iss. 3, pp. 14965-14972 (2016). 